We thank Professor L Symon for permission to study this patient at St Bartholomew's Hospital.

1 Lipid Research Clinics. Manual of laboratory operations. Vol 1. Washington DC: Department of Health Education and Welfare, 1974. (DHEW Publication No (NIH) 75.628.)

${ }^{2}$ Akazawa S. A case of familial type IIa hyperlipoproteinaemia with a huge intracranial xanthoma, hypertension and periarticular bone lesions. Nippon Naika Gakkai Zasshi 1980;69:867-73.

(Accepted 16 February 1984)

Department of Medicine, St Bartholomew's Hospital, London EC1 A REES, MB, MRCP, research registrar

G LEE, MRCP, MRCPATH, lecturer

J STOCKS, PHD, senior hospital biochemist

M A VELLA, MRCP, research registrar

J KATZ, BSC, hospital biochemist

D J GALTON, MD, FRCP, consultant physician

Correspondence to: Dr A Rees, Lipid Laboratory, 53 Barts Close, St Bartholomew's Hospital, London EC1A 7BE.

\section{Plumber's knee: calcinosis cutis after repeated minor trauma in a plumber}

Calcinosis cutis is not uncommon but little is known about its cause, and, surprisingly, it has rarely been reported after trauma. We describe here a case of calcinosis cutis apparently directly related to repeated minor trauma.

\section{Case report}

A 54 year old plumber presented complaining of a swelling below his right knee. This had been present for eight years and had grown larger over the past 12 months. A similar swelling was present beneath the left knee. When questioned directly he described his method of bending water pipes by pulling them with both arms and using either knee as a fulcrum. Examination showed a firm cutaneous swelling $4 \mathrm{~cm}$ in diameter below the right knee. Centrally it was fluctuant and had a small punctum. The lesion beneath the left knee was similar but smaller and not fluctuant.

Surgical exploration of the right sided swelling showed a poorly delineated lesion composed of firm white tissue containing chalky nodules (figure). Histological examination showed an extensive area of calcinosis cutis. The nodules of calcification were up to $4.5 \mathrm{~mm}$ in size, situated in the mid to deep dermis, and surrounded by a giant cell reaction of foreign body type. No pre-existing lesion could be identified. The superficial dermis was histologically normal but the overlying epidermis was hyperkeratotic. Chemical analysis of the dry tissue showed that it contained $16 \cdot 2 \%$ calcium and $10.4 \%$ orthophosphate; oxalate and carbonate were present in trace amounts. Energy dispersive $x$ ray microanalysis confirmed the location of elemental calcium in the nodules and showed no evidence of other metallic elements in the epidermis, dermis, or nodules.

Subsequent serological investigation showed normal values for sodium, potassium, bicarbonate, urea, creatinine, calcium $(2.5 \mathrm{mmol} / \mathrm{l})$, phosphate $(1.01 \mathrm{mmol} / \mathrm{l})$, alkaline and acid phosphatase, and albumin.

\section{Comment}

Four forms of calcinosis cutis are recognised: metastatic calcinosis, subepidermal calcified nodule, dystrophic calcinosis, and idiopathic calcinosis. ${ }^{1}$ Metastatic calcinosis is secondary to hypercalcaemia or hyperphosphataemia, neither of which was present in this patient. Subepidermal calcified nodules usually develop in childhood and classically calcification occurs in the subepidermal zone. This patient acquired his lesions during his working life and the subepidermal zone appeared to be free from calcification. The term dystrophic calcinosis is usually reserved for calcinosis occurring in dermis which has been damaged by connective tissue diseases such as dermatomyositis and scleroderma. Idiopathic calcinosis cutis, which includes the familial tumoral calcinosis and idiopathic scrotal calcinosis, resembles dystrophic calcinosis histologically but there is no identifiable underlying disease. The lesion we describe should strictly be classified as dystrophic calcinosis cutis because there was evidence of preceding trauma.

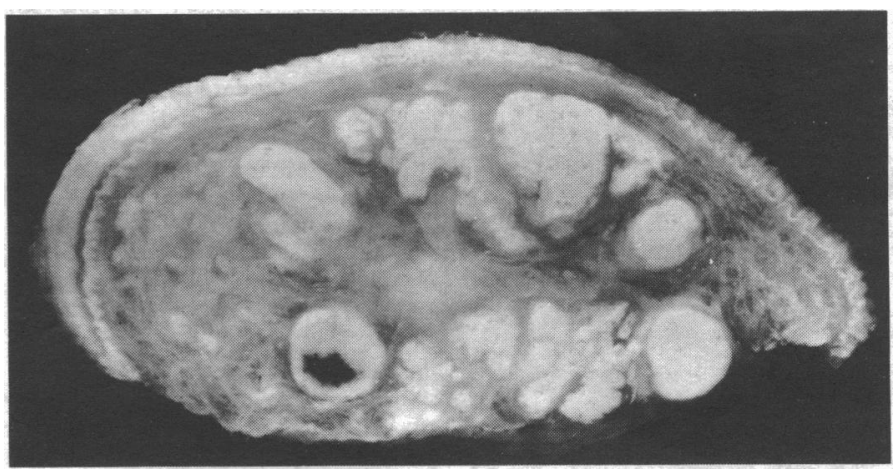

A cut surface of the lesion removed from the right knee showing the multiple chalky nodules situated in the dermis $(\times 4 \cdot 2)$.

To our knowledge calcinosis cutis has only once been reported after repeated trauma. This was in low birth weight neonates in a high dependency unit who had been subjected to multiple heel pricks. ${ }^{2}$ Calcification after repeated trauma does occur in sites other than the skin : in seamstresses and weavers calcification may occur in the gluteal soft tissues after ischiogluteal bursitis. ${ }^{3}$

As little as $10^{-19} \mathrm{~g}$ of an element can be identified with energy dispersive $x$ ray microanalysis. ${ }^{4}$ Using this sensitive technique we were unable to show any of the metals commonly used to make water pipes -for example, copper. It is therefore unlikely that this patient's calcinosis cutis developed secondary to the presence of metal which had got into the dermis through an open wound. We conclude that repeated minor trauma caused by bending water pipes resulted in a form of dystrophic calcinosis cutis to the skin below the knees"plumber's knee."

We thank Mr B R Hopkinson for allowing us to report this case, Mr A Bridge for analysing the tissue chemically, and $\mathrm{Mr} W$ Brackenbury for his photographic help.

${ }^{1}$ Lever WF, Shaumberg-Lever G. Histopathology of the skin 6th ed. Philadelphia: J B Lippincott, 1983.

2 Sell EJ, Hansen RC, Struck-Pierce S. Calcified nodules of the heel: a complication of neonatal intensive care. F Pediatr 1980;96:473-5.

3 Withersty DJ, Chillag SA. Seamstress's bottom. Am Family Physician $1979 ; 19: 85$.

Sumner AT. X ray microanalysis: a histochemical tool for elemental analysis. Histochem $\mathcal{F}$ 1983;15:501-41.

(Accepted 16 March 1984)

Queen's Medical Centre, Nottingham NG7 2UH

I O ELLIS, BM, Bs, lecturer in pathology

$M$ C FOSTER, MB, CHB, registrar in surgery

C WOMACK, $\mathrm{MB}$, BS, senior registrar in pathology

Correspondence to: Dr I O Ellis.

\section{Hidden dangers of sliced bread}

Ingestion of foreign bodies rarely causes complications. We, however, report two cases of gastrointestinal complications due to the inadvertent ingestion of a commonly used bread wrapper clip.

\section{Case reports}

Case 1-A 73 year old edentulous woman presented with a sudden onset of abdominal pain and vomiting. For two months she had been suffering from intermittent abdominal pain, and barium meal examination and oral cholecystography had failed to identify the cause. Examination disclosed a rigid abdomen and absent bowel sounds, and a radiograph showed free gas under the left hemidiaphragm. At laparotomy a linear perforation was found in the upper ileum. The affected bowel was resected and the patient made an uneventful recovery. When the specimen was opened (figure) a bread wrapper clip $2 \times 2 \mathrm{~cm}$ was found to have gripped the intestinal wall, resulting in pressure necrosis and perforation. The patient had no recollection of swallowing the clip.

Case 2-A 52 year old edentulous diabetic woman receiving oral hypo- 
glycaemic treatment presented with a four month history of recurrent colicky abdominal pain and intermittent vomiting. Two years previously a small intestinal lipoma, which had caused an intussusception, had been resected successfully. Examination elicited slight tenderness in the right hypochondrium. Barium meal and follow through examination and oral cholecystography failed to identify the cause. At elective laparotomy various adhesions were divided and a stricture in the terminal ileum identified and resected. When the specimen was opened a bread wrapper clip was found firmly embedded in the intestinal wall and surrounded by a $2 \times 3 \mathrm{~cm}$ area of mucosal ulceration. The patient made a satisfactory postoperative recovery and subsequently remained symptom free.

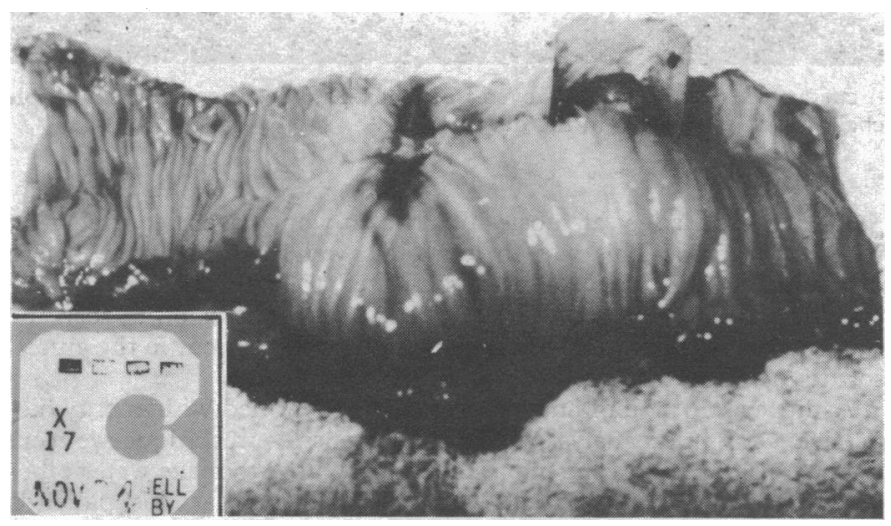

Case 1. Excision specimen of small intestine showing bread wrapper clip clasping and perforating full thickness intestinal wall with adjacent areas of mucosal ulceration.

\section{Comment}

Inadvertent ingestion of foreign bodies-particularly by elderly or edentulous patients-is common but complications are apparently rare. ${ }^{12}$ Our two cases suggest that ingested plastic bread wrapper clips tend to grip portions of the intestinal wall between their "jaws." Ensnaring of less than the full thickness of the intestinal wall by the clip probably causes localised necrosis and sloughing of the mucosa. As a result the clip is released back into the lumen, where it can again become attached to the mucosa at a more distal site. This sequence of events may have accounted for the areas of mucosal ulceration seen in case 1 (figure) proximal to the perforation and for the clinical presentation of intermittent abdominal pain in both patients. If the full thickness of the intestinal wall is grasped perforation (case 1) or stricture (case 2) may occur. Perforation and subacute intestinal obstruction caused by these clips have been described. ${ }^{34}$

In view of the apparent ease with which these clips may be accidentally swallowed and their tendency to damage the small intestine, bakers should seek safer methods of sealing bread wrappers. At the very least, a warning of the dangers of swallowing these clips should be placed on the bread wrapper.

With the continuing vogue for prepackaged food, physicians should consider ingested foreign bodies as a cause of recurrent abdominal pain, especially in elderly or edentulous patients.

We thank Mr W P Small for permission to report case 2.

${ }^{1}$ McPherson RC, Karlon M, Williams RO. Foreign body perforation of the intestinal tract. $A m \mathcal{F}$ Surg 1957;94:564.

2 Bunker PG. Role of dentistry in the problems of foreign bodies in the air and food passages. F Am Dent Assoc 1962;64:335-7.

${ }^{3}$ Rivron RP, Jones DRB. A hazard of modern life. Lancet 1983;ii:334.

4 Jamison MH, Davis RWW, Maclennan I. A plastic bread-bag clipcause of intermittent intestinal obstruction. Br f Clin Pract 1983;37: 402-3.

(Accepted 7 March 1984)

University of Edinburgh Medical School, Teviot Place, Edinburgh EH8 9AG

N J BUNDRED, MB, BS, research fellow, department of clinical surgery R A S BLACKIE, MB, MRCPATH, lecturer, department of pathology

A N KINGSNORTH, MS, FRCS, lecturer, department of clinical surgery

O EREMIN, FRACS, FRCSED, senior lecturer, department of clinical surgery

Correspondence to: Dr N J Bundred.

\section{Value of test for antinuclear antibodies in rheumatic diseases}

Antibodies to nuclear antigens that fluoresce on testing are useful in diagnosing connective tissue diseases ${ }^{1}$ but are also seen in patients with rheumatoid arthritis, when their presence is thought to predict a more severe form of the disease. ${ }^{2}$ Tests for antinuclear antibodies are increasingly being carried out, and we evaluated the usefulness of the test in a retrospective study.

\section{Patients, methods, and results}

We reviewed the case sheets of 470 consecutive new referrals attending this centre for over four months in 1977 in whom tests for antinuclear antibody and rheumatoid factor had been carried out. Details collected included age, sex, duration of disease, erythrocyte sedimentation rate, and the ultimate clinical diagnosis according to recognised criteria. ${ }^{3}$ The standard test for antinuclear antibodies was performed using indirect fluorescence microscopy with rat liver as the substrate. The two stage test for rheumatoid factor using latex agglutination was carried out, and positive serum samples were retested by serial dilution with sheep red blood cells labelled with immunoglobulin (Rose-Waaler). For both antinuclear antibody and rheumatoid factor titres $>1 / 32$ were regarded as strongly positive.

We studied in more detail 102 of the patients with definite or classic rheumatoid arthritis who had been followed up for at least five years. We noted the use of second line drugs (sodium aurothiomalate, penicillamine, or levamisole), corticosteroids, or cytotoxic drugs and whether minor surgery (hand or foot) or major surgery (synovectomy, osteotomy, or arthroplasty of large joints) had been performed. Indications for drugs that modify disease remained relatively constant during the study.

The table shows the results of tests for antinuclear antibody in all 470 patients. Although results were positive in a higher proportion of patients with rheumatoid arthritis and connective tissue disease, the test was neither sensitive nor specific and strongly positive results were seen in all diagnostic categories. Titres of antinuclear antibody $>1 / 32$ were more common among those strongly positive for rheumatoid factor (28/104 patients) than those weakly positive $(4 / 25)$ or negative $(24 / 341)$ for rheumatoid factor.

Results of tests for antinuclear antibody in patients with rheumatoid arthritis and other rheumatic diseases (figures are numbers (\%) of patients)

\begin{tabular}{|c|c|c|c|}
\hline & Negative & $\begin{array}{c}\text { Weakly } \\
\text { positive }\end{array}$ & $\begin{array}{l}\text { Strongly } \\
\text { positive }\end{array}$ \\
\hline \multicolumn{4}{|c|}{ Initial results in all patients $(n=470)$} \\
\hline $\begin{array}{l}\text { Osteoarthritis }(n=83) \\
\text { Rheumatoid arthritis }(n=156) \\
\text { Connective tissue disease }(n=17) \\
\text { Others } \dagger(n=214)\end{array}$ & $\begin{array}{r}70(84) \\
94(60) \\
11(65) \\
185(86)\end{array}$ & $\begin{array}{l}7(8) \\
26(17) \\
1(6) \\
20(9)\end{array}$ & $\begin{array}{c}6(7) \\
36(23) \\
5(29) \\
9(4)\end{array}$ \\
\hline Total & $360(77)$ & $54(11)$ & $56(12)$ \\
\hline \multicolumn{4}{|c|}{ 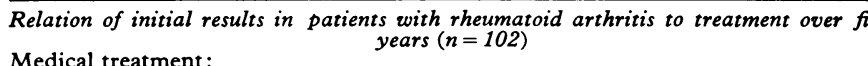 } \\
\hline $\begin{array}{l}\text { Medical treatment: } \\
\text { First line only }(n=45) \\
\text { Cytotoxic drugs or steroids }(n=57)\end{array}$ & $\begin{array}{l}27(44) \\
34(56)\end{array}$ & $\begin{array}{r}7(41) \\
10(59)\end{array}$ & $\begin{array}{l}11(46) \\
13(54)\end{array}$ \\
\hline $\begin{array}{l}\text { Surgical treatment: } \\
\text { None }(n=58) \\
\text { Minor }(n=19) \\
\text { Major }(n=25)\end{array}$ & $\begin{array}{l}32(52) \\
10(16) \\
19(31)\end{array}$ & $\begin{array}{l}9(53) \\
5(29) \\
3(18)\end{array}$ & $\begin{array}{r}17(71) \\
4(17) \\
3(13)\end{array}$ \\
\hline
\end{tabular}

* Systemic lupus erythematosus, progressive sclerosis, polymyositis, mixed connective tissue disease, and undifferentiated connective tissue disease.

tSeronegative arthritis, gout, polymyalgia, and soft tissue rheumatism.

A five year follow up of patients with rheumatoid arthritis showed no significant correlation between the results of the initial tests for antinuclear antibody and the subsequent use of drugs that modify disease or major surgery. The same applied to the results of all tests for antinuclear antibody carried out over five years.

\section{Comment}

Although antinuclear antibodies are found in patients with lupus erythematosus and other connective tissue diseases, they also occur in $16-34 \%$ of patients with rheumatoid arthritis. ${ }^{4}$ Ward et al found that positive results related to the presence of rheumatoid nodules, vasculitis, eye lesions, Felty's syndrome, "drug toxicity," and rheumatoid factors. Condemni et al found a relation with nodules but not the other features, and noted instead correlation with severity of disease by anatomical functional classification. ${ }^{2}$ Both studies considered patients with established rheumatoid arthritis already attending hospital.

In this study we assessed the prognostic value of testing for antinuclear antibody at the time of first attendance. To overcome the problems of a retrospective study of hospital case records we used use of 